\title{
Smoking cessation at the pharmacy: feasibility and benefits based on a French observational study with six-month follow-up
}

This article was published in the following Dove Press journal: Substance Abuse and Rehabilitation

\author{
Brigitte Bouchet-Benezech' \\ Bernard Champanet ${ }^{2}$ \\ Pierre Rouzaud ${ }^{3}$ \\ 'Department of Addiction Medicine, \\ Albi Hospital, Albi, France; ${ }^{2}$ Pharmacy, \\ Place de la Maladrerie, Albi, France \\ ${ }^{3}$ Tabac et Liberté, Toulouse, France
}

Correspondence: Brigitte

Bouchet-Benezech

Department of Addiction Medicine, Albi Hospital, 22 Boulevard General Sibille, 81000 Albi, France

Tel +33563474432

Fax +33 563474812

Email brigitte.bouchet-benezech@ch-albi. rss.fr
Background: In comparison to other European countries, the number of smokers remains high in France. Approximately five million smokers wish to quit within the year and need support that is local, easily accessible, and efficient. As public health actors, pharmacists could provide this service. The Sevrage Tabagique à l'Officine: Smoking Cessation Program at the Pharmacy (STOP) study was carried out to explore the feasibility of a smoking cessation program provided at pharmacies.

Materials and methods: Pharmacists participating in the study were trained to provide a smoking cessation program to smokers recruited at the pharmacy, which included five pharmaceutical interviews in six months, along with counseling and support, in addition to nicotine replacement therapy. This observational, longitudinal, prospective study assessed the feasibility of the program by measuring the percentage of participants remaining at the six-month visit, the proportion of invited pharmacies that actually participated in the program, and the benefits to the participants.

Results: Ninety pharmacies were invited to participate, 79 (88\%) pharmacies entered the study, and 49 (54\%) included study participants and treated 227 subjects with a mean age of 45.4 years. At six months, $23.3 \%$ of participants attended their follow-up visit, among which $75 \%$ had been abstinent since their last visit and more than half for 90 days. From the second follow-up visit, their Short Form 12 physical and mental health composite scores were improved in comparison with baseline. Participants and pharmacists all reported being highly satisfied with the program; however, the attrition rate was substantial, possibly due to some study limitations.

Conclusion: The provision of support for smoking cessation by pharmacies is feasible despite some barriers such as lack of awareness and difficulty to change habits for the smokers or lack of time and training for the pharmacists. The conditions necessary for this program to be implemented on a large scale include training of pharmacists, access to a private space in the pharmacy, remuneration for the pharmaceutical interviews, collaboration with other health care professionals, and an effective communications program regarding the service, both inside and outside of pharmacies. The relatively low number of participants at the end of the study could be improved by increasing awareness of the program, involving health authorities, and enlarging the number of pharmacies engaged in the program.

Keywords: counseling, nicotine replacement therapy, prevention, training

\section{Introduction}

In France, tobacco use is estimated to cause 78,000 premature deaths every year, ${ }^{1}$ and smoking prevalence remains high (34\% in those $15-75$ years of age $)^{2}$ in comparison 
with other countries. Among the 16 million smokers in France, 30\% declare wanting to quit in the next 12 months; ${ }^{3}$ however, only 750,000 persons stop smoking for one year. ${ }^{4}$ To improve the situation, the Ministry of Social Affairs and Health launched a national smoking reduction program, which was part of the 2014-2019 Cancer Plan. ${ }^{5}$

These actions against tobacco involved health care professionals, including pharmacists who represent the third largest health care professional group worldwide. ${ }^{6}$ In recent years, their role has been extended from medication suppliers to public health actors engaged in education and prevention. ${ }^{7}$ The ability of pharmacists to add counseling to nicotine replacement therapy (NRT) delivery has been widely reported in the literature. ${ }^{7-11}$ These programs usually show a high degree of heterogeneity in the type of program used and the quit rates obtained. In the Brown et $\mathrm{al}^{8}$ review of randomized controlled trials performed in community pharmacies, the 26 -week quit rates varied from $1.3 \%$ to $46.2 \%$. Several studies have confirmed the benefit of combined medical and behavioral treatments compared to usual care, especially when the follow-up is at least for six months. ${ }^{10,12}$ All forms of NRT (patch, gum, pastilles, lozenges, tablets, sprays, inhalers) help people quit smoking, doubling the odds of quitting. ${ }^{13-15}$ Combining patches and lozenges is more efficient than patches alone. ${ }^{16}$ Combining counseling and NRT is more successful than either alone. ${ }^{17}$ The French public health code states that pharmacists "contribute to primary care and are involved in therapeutic education and patient follow-up". ${ }^{18}$ Recently, French health authorities have asked pharmacists to perform remunerated "structured pharmaceutical interviews" of patients who are asthmatic or being treated with oral anticoagulants. ${ }^{19}$ Similarly, pharmaceutical interviews could be used to support smokers willing to quit their habit: $81 \%$ of French pharmacy customers consider that preventive, educational, or advisory activities such as smoking cessation support or dietary advice are part of the pharmacist's role. ${ }^{20}$ Pharmacists are frequently in contact with healthy people as well as patients, notably smokers with comorbidities needing chronic medical treatment. ${ }^{21}$ In France, it has been estimated that every day four million people ${ }^{22}$ enter one of the 22,324 pharmacies. ${ }^{23}$ Pharmacists are currently the only supplier of NRT, either as over-the-counter or prescribed products. Since 1999, a prescription for NRT is no longer mandatory in France. In 2016, pharmacists supplied NRT products to more than two million smokers. ${ }^{24}$ In comparison, the mean number of patients followed by a smoking cessation specialist is approximately $25,{ }^{1}$ and the mean waiting time to obtain an appointment with a smoking cessation specialist is over
12 days and is increasing from year to year. ${ }^{4}$ Pharmacies are easily and widely accessible, covering urban and rural areas. They offer long opening hours, allow frequent contact between the individual and health care professionals, can hand out informative material, and provide a confidential environment for customized smoking cessation counseling. Moreover, pharmacists have the professional skills to inform customers about the medications immediately available at the pharmacy and can follow them up. ${ }^{25}$

Considering the strong potential of pharmacists, a group of French experts, specialists in smoking cessation (a pharmacist, physician, and pneumologist) decided to perform the STOP (Sevrage Tabagique à l'Officine: Smoking Cessation Program at the Pharmacy) study ${ }^{26}$ to evaluate the impact of pharmaceutical interviews on smoking cessation. The scientific committee, comprising the authors, proposed the protocol, wrote the educational material, validated study documents, and trained the investigators in techniques for smoking cessation and the management of the study.

The primary objective was to assess the feasibility of a smoking cessation support by measuring the percentage of participants remaining at the six-month visit. Some of the secondary outcomes also assessed the program feasibility: proportion of pharmacies that was invited and actually participated in the program, duration of interviews, participant's quality of life, participant satisfaction, and investigator satisfaction. Other outcomes measured the benefits to the participants.

\section{Materials and methods Study design}

This observational, longitudinal, prospective study aimed at evaluating the feasibility of a smoking cessation program implemented at the pharmacy. Every smoker was scheduled to make five visits comprising face-to-face interviews with the investigator (one inclusion visit, $\mathrm{V} 0$; three visits in three months, V1 to V3; and one visit at six months, V4), and which usually corresponded with the supply of NRT or other pharmaceutical products.

Pharmacies located in France, mainly in the southwest $(n=90)$, were selected according to the following criteria: the pharmacy should be close to its customers, should participate to the training session, and have a private space to be used for the interviews. Pharmacies that expressed an interest and agreed to participate were accepted and were followed by a research associate.

The study was declared to the French National Pharmacist Council (Conseil National de l'Ordre des Pharmaciens: 
CNOP) who did not request any modifications. The research organization in charge of the study obtained permission to collect the relevant health data from the French independent administrative authority responsible for protecting privacy and personal data (CNIL: Commission Nationale de l'Informatique et des Libertés/Commission for Computing and Liberties), and all data were hosted by an authorized web hosting company. As the study was observational and conducted by health professionals, specific ethical approval was not required. Pharmacist investigators answered a questionnaire regarding their pharmacy and entered the study by signing a confidential agreement. Investigators obtained oral consent from all participants, which was recorded in their study files. Participants received an information letter explaining the study, and all information was collected anonymously.

As the study sponsor, Pierre Fabre Health Care Laboratories (Castres, France), provided financial support for the printing of the educational material used in the study as well as the contract research organization in charge of monitoring the study, quality control, and analysis of the results. Pierre Fabre also offered honoraria to the investigators, which covered the time they spent in interviews, and were consistent with the honorarium given by the French national health care insurance scheme for pharmaceutical interviews.

\section{Participants}

A sample size of 400 subjects was calculated to allow for an estimated proportion of $50 \%$ (arbitrary ratio) of subjects attending the six-month pharmaceutical interview, with a $4.9 \%$ confidence interval and a $5 \% \alpha$ risk. The recruitment of 90 pharmacies was planned in order to obtain 60 active pharmacies, each recruiting an average of 6-7 participants within a 12-month period. Smokers were asked if they would like to enter the program when visiting a pharmacy to initiate NRT or to buy NRT or other products, such as antitussives. To encourage participation, only minimal constraints were applied. Smoking cessation could have been initiated by a health care professional outside the pharmacy, by the individuals themselves, or by the pharmacist, and participants were given their choice of NRT product. Inclusion of subjects was dissociated from NRT purchase. Participants were required to pay for their NRT; however, depending on their social insurance coverage, some could obtain partial reimbursement (50-150 euros/year) from their health insurance agency if the products were prescribed.

To be included in the study, smokers had to be aged over 18 years, habitual cigarette smokers (manufactured or "roll your own"), smoking at least one cigarette per day for at least five years, and agree to participate in the study by giving their oral consent. They were also required to be willing to fill in the self-report questionnaires, be either starting or already using NRT and intending to continue their treatment, and to be fluent in French. Participants did not receive compensation to participate in the study. Smokers already participating in another study or pregnant women were not included. A private space was set aside in each pharmacy for the face-toface interviews. The pharmaceutical interviews included a five-minute discussion on general follow-up and a ten-minute discussion on one or more of several specific topics selected by the participant: the perceived risks of quitting, teenagers and tobacco use, the benefits of smoking cessation, dependence, drug addiction, the ingredients in a cigarette, helping pregnant women to stop smoking (although pregnancy was an exclusion criterion, this information interested some smokers), and smoking cessation in case of surgery.

\section{Measures/assessments}

The primary outcome was the percentage of participants remaining at the six-month visit. The six-month end point was chosen from the study of Lally et al, ${ }^{27}$ who demonstrated that the average time needed to form a habit is around 66 days, meaning that three months are needed after quitting to maintain the new habit of not smoking. Therefore, the six-month end point seemed appropriate for evaluating the consolidation of smoking cessation.

The information and parameters collected during the visits are presented in Table 1 and detailed below. At V0, the assessment included demographic information (age, sex, daily cigarette consumption, and subject questioning about smoking-related illnesses [namely, cancer, cardiovascular, respiratory, or gastrointestinal diseases and retinal degenerative disease] and metabolic, sexual, and sleep disorders, dependence evaluation [the Fagerström questionnaire: 0-2, no dependence; 3-4, low; 5-6, moderate; 7-8, high; 9-10, very high dependence], and motivation to quit on a visual analog scale [VAS] from 0: "I am not at all motivated to quit smoking" to 10: "I am very motivated to stop smoking"). During the visits, information was provided on smoking cessation, and on the interview topic(s) selected by the participants. The duration of the interview, and the use and type of NRT supplied to the participant were recorded. The Short Form 12 (SF-12) questionnaire was administered to evaluate the participant's general health and quality of life, and three questions $(12,13,14)$ from the Smoking Cessation Quality of Life (SCQoL) questionnaire were used to 
Table I Study parameters measured by study visits

\begin{tabular}{llllll}
\hline Study visits & V0 & VI & V2 & V3 & V4 \\
\hline Time of visits & At inclusion & At I month & At 2 months & At 3 months & At 6 months \\
\hline Subjects attending visits & $\mathrm{n}=227(100 \%)$ & $\mathrm{n}=132$ & $\mathrm{n}=88$ & $\mathrm{n}=65$ & $\mathrm{n}=53(23.3 \%)$ \\
& & $(58.1 \%)$ & $(38.8 \%)$ & $(28.6 \%)$ & \\
\hline
\end{tabular}

\begin{tabular}{|c|c|c|c|c|c|}
\hline Demographic information & & & & & \\
\hline Age, mean $\pm S D(n)$ & $45.5 \pm 13.6(227)$ & & & & \\
\hline Sex (female), \% (n) & $64.3(227)$ & & & & \\
\hline Cigarette consumption, $\%$ & & & & & \\
\hline $\mathrm{I}-10 \mathrm{cig} / \mathrm{d}$ & 17 & & & & \\
\hline $\mathrm{II}-22 \mathrm{cig} / \mathrm{d}$ & 56 & & & & \\
\hline $21-30 \mathrm{cig} / \mathrm{d}$ & 22 & & & & \\
\hline$>30 \mathrm{cig} / \mathrm{d}$ & 5 & & & & \\
\hline At least one possible smoking-related illness, $\%$ & 75 & & & & \\
\hline Fagerström score (out of 10 ), mean $\pm S D$ & $4.96 \pm 2.37$ & & & & \\
\hline Motivation to quit smoking (VAS 0-10), mean \pm SD & $7.3 \pm 2.2$ & & & & \\
\hline NRT users, \% & 96.9 & 86.4 & 84.1 & 69.2 & 45.3 \\
\hline Duration of the interview (minutes), mean $\pm \mathrm{SD}$ & $\mathrm{n}=222$ & $n=129$ & $\mathrm{n}=83$ & $\mathrm{n}=62$ & $n=49$ \\
\hline Average duration & $29.7 \pm 13.1$ & $22.4 \pm 9.9$ & $20.5 \pm 7.3$ & $22.9 \pm 9.6$ & $20.7 \pm 9.1$ \\
\hline Main topic selected for the interview, \% & & & & & \\
\hline Benefits of smoking cessation & 37.2 & 26.6 & & & \\
\hline Helping pregnant women to stop & & & 20.7 & & \\
\hline Perceived risks of quitting & & & & 27.1 & 18.8 \\
\hline Quality of life: SF-12, mean \pm SD & $\mathrm{n}=226$ & $n=130$ & $\mathrm{n}=86$ & $\mathrm{n}=64$ & $\mathrm{n}=5 \mathrm{I}$ \\
\hline Physical composite score & $49.1 \pm 9.6$ & $50.7 \pm 9.0$ & $51.9 \pm 7.5$ & $5 \mathrm{I} .4 \pm 8.4$ & $53.54 \pm 7.8$ \\
\hline Mental composite score & $42.6 \pm 10.8$ & $46.1 \pm 10.5$ & $47.5 \pm 10.4$ & $49.4 \pm 9.2$ & $48.96 \pm 11.5$ \\
\hline SF- 12 for the 53 completers, mean $\pm S D$ & $\mathrm{n}=53$ & $\mathrm{n}=49$ & $\mathrm{n}=52$ & $\mathrm{n}=49$ & $n=51$ \\
\hline Physical composite score & $48.0 \pm 10.3$ & $51.4 \pm 9.8$ & $52.0 \pm 8.4$ & $52.0 \pm 8.2$ & $53.5 \pm 7.8$ \\
\hline Mental composite score & $42.8 \pm 11.3$ & $47.7 \pm 11.0$ & $47.2 \pm 11.4$ & $49.4 \pm 9.6$ & $49.0 \pm 11.5$ \\
\hline SCQoL subscores, mean \pm SD & $\mathrm{n}=226$ & $\mathrm{n}=130$ & $\mathrm{n}=87$ & $\mathrm{n}=64$ & $\mathrm{n}=5 \mathrm{I}$ \\
\hline Self-control & $39.3 \pm 17.5$ & $51.4 \pm 18.9$ & $53.5 \pm 19.6$ & $58.2 \pm 18.3$ & $59.2 \pm 17.4$ \\
\hline Anxiety & $51.8 \pm 26.2$ & $61.4 \pm 24.5$ & $66.2 \pm 24.9$ & $71.9 \pm 22.6$ & $69.1 \pm 21.9$ \\
\hline Social interactions & $40.5 \pm 11.2$ & $43.2 \pm 11.02$ & $45.8 \pm 11.2$ & $46.5 \pm 9.8$ & $45.8 \pm 13.8$ \\
\hline Sleep & $52.4 \pm 16.8$ & $53.30 \pm 17.1$ & $55.4 I \pm I 5.7$ & $53.8 \pm 15.8$ & $57.6 \pm 18.4$ \\
\hline Subject receptiveness (VAS $0-10$ ), mean $\pm S D$ & & $8.4 \pm 2.0$ & $8.6 \pm 1.8$ & $8.8 \pm 1.7$ & $8.6 \pm 2.4$ \\
\hline Questionnaire on smoking cessation & & & & & \\
\hline Number of cigarettes per day, mean $\pm S D$ & & $4.3 \pm 6.4$ & $3.3 \pm 5.5$ & $2.5 \pm 5.0$ & $1.4 \pm 3.6$ \\
\hline Weight gain since the last visit, \% of yes & & 33.6 & 45.5 & 40.0 & 49.1 \\
\hline Participant satisfaction (CSQ8), mean \pm SD & & & & $\mathrm{n}=65$ & $n=53$ \\
\hline Global score (out of 4) & & & & $3.6 \pm 0.4$ & $3.7 \pm 0.4$ \\
\hline $\begin{array}{l}\text { Pharmacist satisfaction (VAS } 0=\text { not at all, } 10=\text { very useful), } \\
\text { mean } \pm \text { SD }\end{array}$ & & & & & $\mathrm{n}=20$ \\
\hline "Is the STOP study useful to my pharmaceutical practice?" & & & & & $8.1 \pm 1.5$ \\
\hline "Is the STOP study adapted to my pharmaceutical practice?" & & & & & $7.5 \pm 1.2$ \\
\hline "Is the STOP study adapted to my clients?" & & & & & $7.1 \pm 1.2$ \\
\hline
\end{tabular}

Abbreviations: VAS, visual analog scale; NRT, nicotine replacement therapy; SF-12, Short Form 12; SCQoL, Smoking Cessation Quality of Life; CSQ8, Client Satisfaction Questionnaire; STOP, Sevrage Tabagique à l'Officine: Smoking Cessation Program at the Pharmacy.

obtain data specifically related to smoking cessation. These three questions, regrouping eight different questions, were categorized into four subgroups assessing self-control, anxiety, social interactions, and sleep. When available at the pharmacy, a CO tester was used to motivate smokers to quit. At visits V1, V2, V3, and V4, the subjects' receptiveness (“do you think the subject is receptive?" on a VAS from 0: not at all receptive to 10: very receptive), their willingness to stop the study ("does the subject want to quit the study?" Yes or No), and the reasons for stopping (smoking cessation, wish to stop the visits, relapse) were recorded. A questionnaire on smoking cessation asking for the number of days without 
smoking ("How many days has it been since you last smoked a cigarette?"), number of cigarettes smoked ("Since your last visit, how many cigarettes in average did you smoke per day?"), compliance ("Since your last visit, did you forget to take your nicotine replacement therapy?"), and weight gain (“Since your last visit, have you gained weight?", if yes "how much?") was administered. There were additional questions at V3 and V4 on participant satisfaction ("Globally, how would you rate your level of satisfaction with the service provided?"), which was measured with the Client Satisfaction Questionnaire (CSQ8) and additional questions at V4 on pharmacist satisfaction, measured with a VAS.

\section{Statistics}

No missing data were replaced. The analysis was performed with $\mathrm{SAS}^{\circledR}$ version 9.4. Quality control was performed by the research associate.

Quantitative variables were described by the mean, standard deviation, median if relevant, and number of included values. Qualitative variables were described by number and percentages of non-missing data. Analyses were performed on the global population of included subjects and on all the pharmacies having included participants. Two-sided test and type I error of 0.05 were applied as standard. Bonferroni correction was used to control type I error in cases of multiple comparisons. A new critical value was obtained by dividing 0.05 by the number of tests. Paired $t$-tests (with Bonferroni correction) were performed to compare intraindividual change among time for SF-12 score and SCQoL scale. The new threshold corrected by the Bonferroni method (ie, $0.05 / 5=0.01)$ was $\alpha^{\prime}=0.01$. The primary outcome was used to appreciate the feasibility of the smoking cessation support, and some of the secondary outcomes also assessed the program feasibility: duration of interviews reflecting the involvement of pharmacists and participants, participant's quality of life, participant satisfaction measured by CSQ8, and investigator satisfaction measured by VAS. Other outcomes including smoking abstinence, use of NRT, and weight gain that illustrate the benefits to the participants were reported.

\section{Results}

\section{Characteristics of study pharmacies}

Ninety pharmacies were invited to participate, of which 79 $(88 \%)$ entered the study. Of the 79 pharmacies, $49(62 \%)$ recruited study participants and treated 227 subjects. One month before the start of the study, 101 pharmacists and employees from 79 pharmacies were trained on the smoking cessation program (pharmaceutical interviews, study material, case report form, pharmacovigilance form, and questionnaires) in a 3.5-hour course. The recruiting pharmacies $(n=49)$ followed an average of 4.6 smokers (minimum 1 , maximum 14). For each pharmacy which performed this study assessment $(n=38)$, the mean number of customers initiating smoking cessation was 22 per year. Most of the 79 included pharmacies were in urban or suburban areas $(61 \%)$ or inside a shopping center (11\%), 56\% had been trained previously by health services for performing pharmaceutical interviews with patients treated with anticoagulants or products for asthma, and $64 \%$ had a mean number of clients per day exceeding 200. One hundred and one persons $(n=101)$ from the 79 pharmacies were trained in techniques for smoking cessation and the management of the study; however, only 49 pharmacies were successful in including subjects.

\section{Demographic information}

From December 2014 to April 2016, 49 pharmacies recruited 227 participants, who were aged between 19 and 82 years (mean 45.4 years, median 45 years). The inclusion rate was lower than estimated, and the study had to be stopped after 17 months even though the required number of participants was not reached. This was mainly due to the depletion of staff availability and financial resources. At V0, of all participants, $64.3 \%$ were female, and $17 \%$ smoked 1-10 cigarettes per day (cig/d), 56\% 11-22 cig/d, 22\% 21-30 cig/d, and 5\% $>30 \mathrm{cig} / \mathrm{d}$. Approximately $75 \%$ of subjects had at least one possible smoking-related illness, most frequently sleeping disorders $(37.9 \%)$, respiratory disease $(22.9 \%)$, and cardiovascular disease $(22.0 \%)$. At inclusion, $29.9 \%$ of participants had already stopped smoking, while the remainder wanted to stop smoking immediately (13.4\%), the same day (25\%), or later (one week as a median, 31.7\%) (Table 1).

\section{Program participation and retention}

The six-month visit was attended by $23.3 \%$ of participants (Figure 1). Over the course of the study, the participation rate was $100 \%$ at V0 $(n=227), 58 \%$ at V1 $(n=132), 39 \%$ at V2 $(\mathrm{n}=88), 29 \%$ at V3 $(\mathrm{n}=65)$, and $23.3 \%$ at V4 $(\mathrm{n}=53)$. Most (109) of the participants who did not complete the program (174) withdrew for no indicated reason, 32 (18.4\%) expressed their wish to stop the visits, $13(7.5 \%)$ were lost to follow-up, $11(6.3 \%)$ resumed smoking, and $10(5.7 \%)$ quit smoking. As a result of the study design, the study visits usually corresponded with the supply of NRT or other pharmaceutical products; at V0, 96.9\% (220/227) of the participants were with NRT, at V3, 69.2\% (45/65), and at V4, 45.3\% (24/53) (Table 2 and Figure 1). 


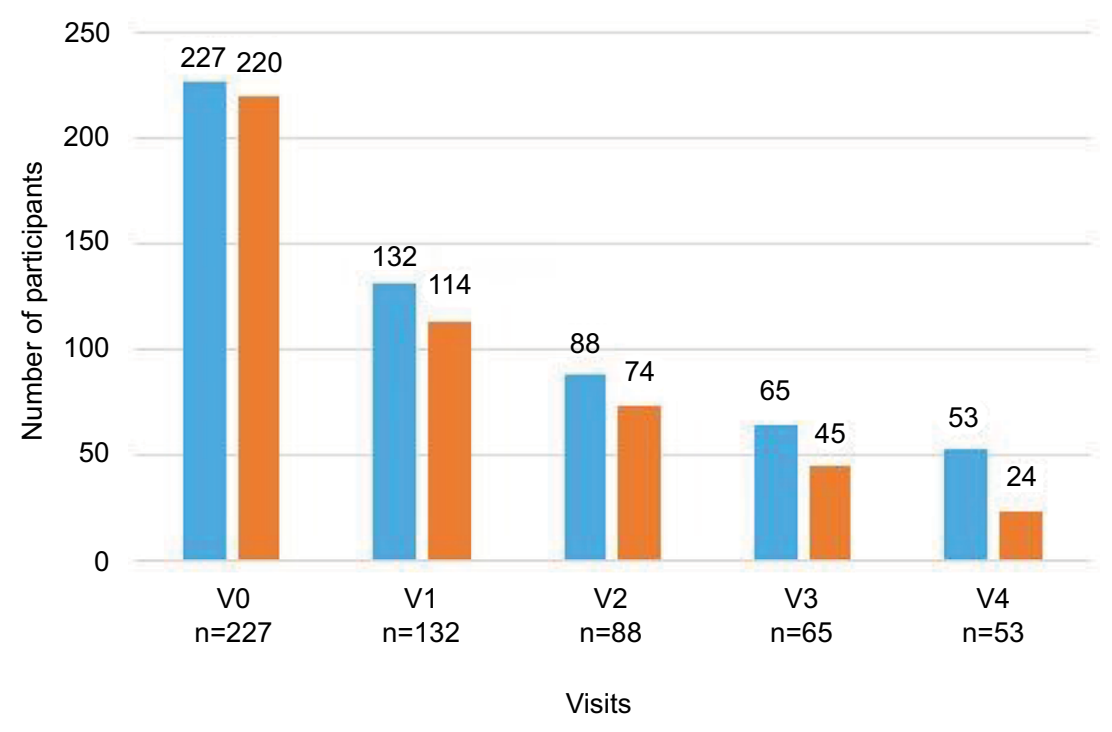

- Number of participants present at the visit

n Number of participants with NRT

Figure I Number of participants present and number using nicotine replacement therapy at each visit.

Abbreviations: NRT, nicotine replacement therapy; V0, inclusion visit; VI, visit at I month; V2, visit at 2 months; V3, visit at 3 months; V4, visit at 6 months.

Table 2 Participant flow and reasons for withdrawal (several reasons were possible)

\begin{tabular}{|c|c|c|c|c|c|c|c|c|}
\hline $\begin{array}{l}\text { Number } \\
\text { of patients } \\
\text { present at visit }\end{array}$ & $\begin{array}{l}\text { Withdrawal } \\
\text { period }\end{array}$ & $\begin{array}{l}\text { Withdrawal with } \\
\text { no indicated } \\
\text { reason }\end{array}$ & $\begin{array}{l}\text { Wishes to } \\
\text { stop the } \\
\text { visits }\end{array}$ & $\begin{array}{l}\text { Lost to } \\
\text { follow- } \\
\text { up }\end{array}$ & Relapse & $\begin{array}{l}\text { Smoking } \\
\text { cessation }\end{array}$ & $\begin{array}{l}\text { Did not meet } \\
\text { inclusion } \\
\text { criteria }\end{array}$ & Comments \\
\hline \multicolumn{9}{|l|}{$\mathrm{V} 0=227$} \\
\hline$V I=132$ & Vo-VI & 54 & 24 & 8 & 2 & I & I & $\begin{array}{l}5 \text { not present at } \mathrm{VI} \\
\text { but present at } \mathrm{V} 2\end{array}$ \\
\hline$V 2=88$ & VI-V2 & 32 & 4 & 2 & 6 & 4 & & $\begin{array}{l}\text { I not present at } \mathrm{V} 2 \\
\text { but present at } \mathrm{V} 3\end{array}$ \\
\hline$V 3=65$ & V2-V3 & II & 3 & 2 & 3 & 4 & & $\begin{array}{l}3 \text { not present at } V 3 \\
\text { but present at } V 4\end{array}$ \\
\hline$V 4=53$ & V3-V4 & 12 & I & I & & I & & \\
\hline
\end{tabular}

Abbreviations: V0, inclusion visit; VI, visit at I month; V2, visit at 2 months; V3, visit at 3 months; V4, visit at 6 months.

\section{Interview topics selected and duration of interviews}

The three main topics selected for the pharmaceutical interview at V0 were "benefits of smoking cessation" (37.2\%), "ingredients in a cigarette" (18.8\%), and "dependence" (9.7\%) showing the participant's interest in improving his/ her knowledge on the disadvantages of smoking and the benefits of quitting smoking. The average duration of the interviews was 25 minutes. More time was spent for V0 (mean=29.7 minutes), than for the following visits (mean time of visit for $\mathrm{V} 1=22.4$ minutes, V2 $=20.5$ minutes, $\mathrm{V} 3=22.9$ minutes, and V4=20.7 minutes). The median duration was 30 minutes for $\mathrm{V} 0$ and 20 minutes for each of the other visits (Table 1).

\section{Health status and quality of life: SF- I 2 and SCQoL}

The SF-12 physical and mental health composite scores between V0 and V1-V4 are summarized in Figure 2. The self-control and social interaction scores also improved significantly between V0 and other visits. Anxiety scores decreased significantly between V0 and other visits, while sleep did not show any significant change between $\mathrm{V} 0$ and the other visits. There was no statistically significant (significance threshold $p<0.01$ ) change between V3 and V4 (approximately third and sixth months) in all these parameters. The results were similar for the completer group $(n=53)$ in comparison to their baseline, except that the SF-12 mental health composite score and social interaction score improvements did not reach 

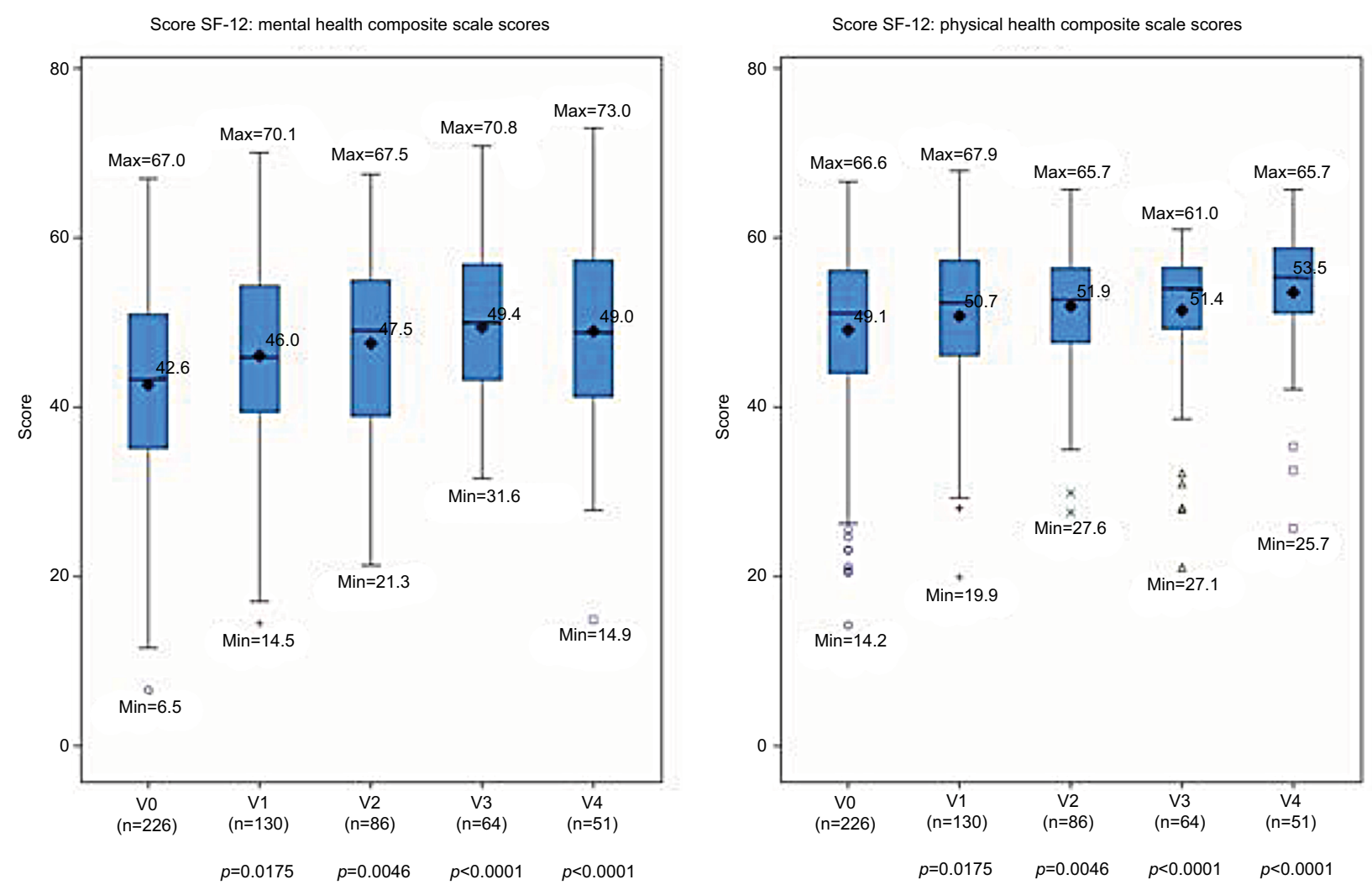

Figure 2 SFI 2 physical and mental health composite scores.

Abbreviations: SF-12, Short Form 12; min, minimum; max, maximum; V0, inclusion visit; VI, visit at I month; V2, visit at 2 months; V3, visit at 3 months; V4, visit at 6 months.

significance between V0 and V1; for the 53 completers, the baseline value of the SF-12 physical dimension was 48.0 and changed to 51.4 ( $p=0.0037$ versus baseline) at $\mathrm{V} 1,52.0$ $(p=0.0019)$ at $\mathrm{V} 2,52.0(p=0.0011)$ at $\mathrm{V} 3$, and $53.5(p<0.001)$ at $\mathrm{V} 4$; for the mental dimension, the baseline value was 42.8 and changed to 47.7 ( $p=0.0175$ versus baseline) at $\mathrm{V} 1,47.2$ $(p=0.0046)$ at $\mathrm{V} 2,49.4(p<0.001)$ at $\mathrm{V} 3$, and $49.0(p<0.001)$ at V4 (Table 1).

\section{Subject satisfaction: CSQ8}

Over $98 \%$ of subjects reported that the service provided was "very satisfying" or "globally satisfying" and the quality of the service was "excellent" or "good". Over 95\% of subjects scored the amount of help received as "very satisfying" or "globally satisfying". Over $96 \%$ of subjects stated that "yes indeed" or "yes in general" they had received the kind of service they wanted. At six months, $100 \%$ of subjects said that they would recommend the program ("yes I think" or "yes absolutely") to a friend and that they would take part in the program again in the event of a relapse. Participants were satisfied with the service, with a mean satisfaction score of $3.7 \pm 0.4$ from a maximum of 4 (Table 1 ).

\section{Investigator satisfaction}

Among the investigators, $40 \%$ (who had recruited $55 \%$ of the participants) returned the satisfaction questionnaire with the following answers. With respect to the usefulness of the program ("Is the STOP study useful to my pharmaceutical practice?"; rated from $0=$ not at all to $10=$ very useful), the average score was $8.1 \pm 1.5$. Regarding the suitability of the program ("Is the STOP study adapted to my pharmaceutical practice or to my clients?"; rated from $0=$ not at all to $10=$ very well adapted), the average score was $7.5 \pm 1.2$ for the pharmaceutical practice and $7.1 \pm 1.2$ for the clients (Table 1). Participant receptiveness, as measured by a VAS (0-10), remained high throughout the study and was between $8.4 \pm 2.0$ at $\mathrm{V} 1$ and $8.6 \pm 2.4$ at V4.

\section{Smoking abstinence}

At six months, 75\% (40/53) of completers and 18\% (40/227) of all participants reported abstinence since their previous visit.

\section{Use of NRT}

At V0, 97\% of participants were using NRT (Figure 1) or wanted to quit in either short or long term. The types of NRT 
chosen by the participants were patches alone (38.3\%), buccal formulations (pastilles, lozenges, gums, tablets; 26.4\%), and patches combined with buccal forms (26.9\%). At six months, $45.3 \%$ of patients were still using NRT: patches alone (17\%), buccal forms alone $(20.8 \%)$, or the combination $(7.5 \%)$.

\section{Weight gain}

Based on participant declaration, the percentage of participants reporting weight gain since their last visit was $33.6 \%$ (44/131) at V1, 45.5\% (40/88) at V2, 40\% (26/65) at V3, and $49.1 \%(26 / 53)$ at V4, and in those who gained weight, the average increase since the previous visit was, depending on the visit, between 2 and $2.5 \mathrm{~kg}$.

\section{Safety}

No adverse effects were reported, and no pharmacovigilance declaration was registered during the study.

\section{Discussion}

The primary objective of this study was to evaluate the feasibility of a smoking cessation program delivered by pharmacists in pharmacies. The results supported this objective, with participant compliance with the interviews, evaluated by measuring the percentage of subjects attending their six-month visit, at $23.3 \%$ (53 out of 227 subjects completed the study). This relatively high attrition rate might be due to several factors such as lack of awareness-raising campaign or difficulty to change habits. Moreover, to minimize the constraints associated with the program and encourage smokers to join the study, the dates of the study visits were not fixed in advance, and visits were arranged around the time that their pharmaceutical products (NRT or others) were supplied, and hence the similar profiles between participant attendance and NRT supply (Figure 1). The flexibility in the timing of visits could partly explain the high attrition rate. This observational study was performed in real-life conditions without national support through communication and awareness campaigns. Greater visibility, such as bigger displays inside and outside the pharmacy, could have increased the number of participants. The proportion of women in the study sample was greater than in the French population who smoke; however, this reflects the higher percentage of women as pharmacy customers. ${ }^{20}$ The characteristics of the completers were similar to the total study population. Therefore, it was not possible to define a particular profile of smokers to be targeted more specifically. The main evaluation criterion (percentage of subjects present at V4) is original, and to our knowledge, has not been used in another study.
For this reason, a direct comparison with other pharmacybased smoking cessation programs is difficult. The percentage of subjects present at one month $(58 \%)$ was close to the participation rate $(49.7 \%)$ reported by Costello et a ${ }^{28}$ at five weeks in a smoking cessation program comprising three interviews and free NRT delivery. Similarly, Le Faou et al ${ }^{29}$ reported that among 39,340 French smokers who consulted for smoking cessation, only $56.5 \%$ returned for their second visit. The tobacco quit rate, usually used as the main criteria in smoking cessation studies, was not the main objective in our study. However, the smoking abstinence rate was good at six months, with 75\% (40/53) of completers and 18\% (40/227) of all participants reporting abstinence since their previous visit, while 30 participants were abstinent for at least 90 days. A few of the non-completers withdrew from the study as they had stopped smoking (Table 2) but were not included as abstinent. The subjects' quality of life improved at each visit in comparison to baseline (Figure 2), and notably for the 53 completers, there was an improvement of the SF-12 physical and mental dimensions. Self-control and social interactions were also improved. Anxiety was decreased, and sleep did not deteriorate. The improvement in quality of life is an argument to convince smokers, who frequently fear that quitting smoking will affect their social life. ${ }^{30}$

The positive role played by the pharmacist was patent. Pharmacists demonstrated strong involvement, as shown by their assiduous participation in the training sessions and the time spent in interviews, with a median of 30 minutes for the inclusion visit and 20 minutes for the visits V1-V4 showing their commitment. In comparison, Dansou et $\mathrm{al}^{31}$ reported that the usual duration of a first conversation over the counter for smoking cessation was from five to ten minutes. At V4, only half of the subjects used NRT, showing that NRT renewal was not the only one reason for visiting the pharmacy. Subject satisfaction measured by CSQ8 was high, with over $95 \%$ of subjects satisfied with the type, quality, and quantity of services received. Pharmacist satisfaction was also high: the program was appreciated as useful, adapted to the pharmaceutical practice and the participants. As a result of the study design, NRT was combined with pharmaceutical interviews. NRT contribution to the program feasibility was not measured; however, it probably facilitated the participation of smokers to the program and participated to the benefits such as improvement of quality of life. Access to NRT was a success factor, even though this was paid for by the participants. The combination of patches and buccal NRT forms was most often used. 


\section{Comparison with other smoking cessation programs at pharmacies}

A representative sample of 290 French pharmacies were contacted in 2002, to evaluate their activity in smoking cessation. ${ }^{32}$ Among the 82 responders, $85 \%$ reported offering counseling for smoking cessation; however, only $37 \%$ of pharmacists were trained, mostly by pharmaceutical companies. Numerous groups, such as private or public organizations or associations including the Ordre National des Pharmaciens, are involved in smoking cessation in France ${ }^{3,33-35}$ and offer different training and programs. ${ }^{31}$ This diversity suggests the need for structured smoking cessation training to be delivered to pharmacy students at university as well as to pharmacists. This program could also benefit other health care providers involved in smoking cessation.

Recently, Madurasinghe et al ${ }^{36}$ published the results of a pilot trial assessing the acceptability and feasibility of conducting smoking cessation interventions in community pharmacies (Smoking Treatment Optimisation in Pharmacies; STOP research program) and reported that in 2014/2015, almost half of the quit attempts in the NHS smoking cessation service in England were made in community pharmacies showing that contribution of pharmacies in smoking cessation is a reality.

In the USA, Shen et $\mathrm{al}^{37}$ analyzed the factors that could possibly explain the differences in quit rate (from $1.1 \%$ to $59.4 \%$ ) at six months in a program including seven pharmacies and 1,235 participants. The quit rate at six months was higher if there were at least three interviews, if the interviews were longer, if there were group sessions instead of a face-to-face interview, and if the subjects reported strong motivation at baseline. Our research confirmed the interest of long interviews but did not experiment group sessions.

In Denmark, Neumann et $a^{38}$ reported the results of a smoking cessation program comprising five counseling sessions and NRT supply free of charge. Overall, $34 \%$ of the 16,377 responders reported six months of continuous abstinence; a quarter of them were followed at the pharmacy. Quit rate was lower in patients who were unemployed or in those with a low educational level. This parameter was not tested in our research.

In Italy, Munarini et $\mathrm{a}^{11}$ performed a smoking cessation study in five pharmacies where staff had been trained for counseling over 15 hours. Interviews were done by a psychologist, and NRT (75\%) or other smoking cessation products was proposed. Smoking cessation was controlled by $\mathrm{CO}$ testing. Among the 216 participants in the study, $53 \%$ wanted to completely quit smoking and $31 \%$ wanted to reduce their cigarette consumption. The quit rate was $28 \%$ at six months and $24.6 \%$ at one year in the group wanting to quit smoking. The obstacles encountered were a lack of time, suggesting the need to compensate staff for the time spent in counseling, the pharmacy clients' lack of knowledge of an existing smoking cessation program, and lack of training for pharmacists. Although not specifically measured, remuneration and training of pharmacists were identified as success factors in our study; conversely, the lack of systematic $\mathrm{CO}$ testing could be considered as a weakness.

Greenhalgh et $\mathrm{al}^{7}$ analyzed 66 publications looking for "what works" in smoking cessation counseling by pharmacists. They provided some useful advice: pharmacists should be trained to increase their confidence (self-confidence but also the confidence of their patients and of other health care professionals); customers should be informed of the existing smoking cessation services offered by pharmacists; a private space should be available in the pharmacies; and the time spent by the pharmacists in counseling should be compensated. Our research took into account these advices except for the dissemination of information on the program which should have been larger.

Since the STOP study, further steps have been taken at a national level, such as the reimbursement for NRT at up to 150 euros per year and the enlargement of NRT prescription, which can now be provided by physicians, dental surgeons, occupational physicians, midwives, masseurs-physiotherapists, and nurses. ${ }^{39}$ Prescriptions for NRT provided by pharmacists are not reimbursed for social security in order to avoid a link between prescriptions and sales. This should reinforce the collaboration between the pharmacists and the other health care professionals who prescribe these products.

\section{Strengths and limitations}

This study used an original criterion to evaluate the feasibility of a smoking cessation intervention delivered through community pharmacies. The program offered most of the key success factors identified in previous publications, and although comparison with previous experience is difficult due to the heterogeneity of the interventions reviewed, the program produced good results. Possible weaknesses of the study include that it was a non-comparative, open study with fewer participants than had been planned, used new evaluation criteria, and that smoking cessation was not systematically controlled with $\mathrm{CO}$ testing. The study was not designed to evaluate the efficacy of the program on quit rate, and the combination of NRT with pharmaceutical interviews did not allow appreciating the contribution of pharmaceutical 
interviews alone. The substantial attrition rate should also be considered. Although staying in the range of what has been reported in other smoking cessation programs, the relatively low number of participants at the end of the study could be improved by increasing awareness of the program through information campaigns, involving health authorities in the financial support, and enlarging the number of pharmacies engaged in the program.

\section{Conclusion}

This original experimental study demonstrated the feasibility of the implementation of a smoking cessation program in pharmacies, with a promising follow-up rate at six months and a steady improvement in the participants' quality of life. The relatively low number of participants at the end of the study could be improved by increasing awareness of the program, involving health authorities, and enlarging the number of pharmacies engaged in the program. Training of pharmacists, the availability of a private space, compensation for the services given, the use of different forms of NRT, collaboration with other health care professionals, advertising the service to pharmacy clients, and ideally the use of a standardized national program are key points to develop the pharmacist's role as a public health actor in smoking cessation.

\section{Acknowledgments}

This work was supported by Pierre Fabre Health Care, Castres, France. The authors are grateful to Dr Anne Laurence Le Faou, ambulatory center of addiction medicine, European Georges Pompidou Hospital, Paris, for her contribution to this work. She supervised the university memoir presenting the intermediate results of the study (Place du pharmacien d'officine dans la prise en charge du sevrage tabagique: résultats intermédiaires de l'étude observationnelle STOP/ Place of the pharmacist in the management of smoking cessation: intermediate results of the STOP observational study). She provided improvements in the methods and reporting, and participated to the discussion in the light of the specific context of the French health system. The authors express their gratitude to all the pharmacists who took part in the study: Cristel Albert, Castres; Edouard Amalric, Montastruc la Conseillere; Xavier Ardillon, St Etienne; Martine Azemar, Clermont l'Herault; Stephanie Blanc, Ramonville St Agne; Eliane Blanc, Montrabe; Remi Boudou, Albi; Vincent Bousquet, Foix; Christelle Boyaud, St Chamond; Henri Caillot, Villefranche de Lauragais; Sebastien Cayotte, Castres; Bernard Champanet, Albi; Jean Marc Chavoix, Muret; Sofia
Cherif, Elne; Marie France Chraibi, Firminy; Isabelle Clouscard, St Jory; Gladys Combettes, Narbonne; Gaelle Corallo, Cahors; Guillaume Dautezac, Castres; Isabelle Escouboue, Lagarrigue; Dominique Fabre, Lavaur; Florence Farrugia, Figeac; Jean Paul Ferrer, Grenade; Daniele Fourniols, Castelnau Montratier; Benoit Galibert, Limoux; Florence Gasquet, Montpellier; Isabelle Gschwind, Toulouse; Jacques Guichard, St Gilles; Christophe Huther, Nancy; Christine Laborde, St Orens de Gameville; Genevieve Lafond, Roanne; Anne Laures, Toulouse; Marie Lebastard, Payrin Augmontel; Elisabeth Marchal, Barentin; Mireille Martignac, Cordes sur Ciel; Bettina Mastrangelo, Lattes; Maud Mingeau, Pouilly sur Loire; Thierry Muller, Sarreguemines; Martine Oldak, Blagnac; Lionel Raynal, Bressols; Isabelle Remy, Thiaucourt; Valerie Rocchi, Allauch; Brigitte Roqueta, Lattes; Patricia Salama, Castelginest; Maxime Segala, Cazouls les Beziers; Agnes Tarodo de la Fuente, St Amans Soult; Laurie Tournut, Lorp Sentaraille; Jean Charles Vautrin, Sete; Luc Vetillart, Sete.

\section{Disclosure}

All the authors declare having received honoraria from Pierre Fabre Health Care for their participation in the study. They report no other conflicts of interest in this work.

\section{References}

1. OFDT (Observatoire Français des Drogues et des Toxicomanies). Évolution du nombre de décès liés au tabac et des ventes de tabac en France depuis 1980 [Evolution of the number of tobacco-related deaths and sales of tobacco in France since 1980]. Available from: http://www.ofdt. fr/statistiques-et-infographie/series-statistiques/tabac-evolution-de-lamortalite-induite-par-la-consommation-et-ventes/. Accessed November 15, 2017. French.

2. INPES (Institut national de prévention et d'éducation pour la santé). Le tabac en France: nouvelles données du Baromètre Santé INPES 2014 [Tobacco in France: new data from the 2014 INPES Health Barometer]. Available from: http://inpes.santepubliquefrance.fr/30000/ actus2015/013-tabac-donnees-barometre-2014.asp. Accessed November 15, 2017. French.

3. Respadd (Reseau de prevention des addictions). Guide de l'addictologie en pharmacie d'officine [Guide to addictology in pharmacy]. Respadd Edition. 2014. Available from: http://www.respadd.org/wp-content/ uploads/2015/08/Guide-addictologie.pdf. Accessed November 15, 2017. French.

4. Alliance contre le tabac. [Health care and smoking cessation in France]. Available from: http://www.alliancecontreletabac.org/F4-maj2012soins-et-aide-au-sevrage-tabagique-en-france.pdf. Accessed November 15, 2017. French.

5. Ministere des affaires sociales et de la santé. National smoking reduction program. Available from: http://social-sante.gouv.fr/IMG/pdf/pnrt20142019_uk.pdf. Accessed November 15, 2017.

6. Chan XH, Wuliji T. Global Pharmacy Workforce and Migration Report: a call for action. 2006. Available from: http://fip.org/files/fip/publications/PharmacyWorkforceMigration.pdf. Accessed November 15, 2017.

7. Greenhalgh T, Macfarlane F, Steed L, Walton R. What works for whom in pharmacist-led smoking cessation support: realist review. BMC Med. 2016;14(1):209. 
8. Brown TJ, Todd A, O'Malley CL, et al. Community pharmacy-delivered interventions for public health priorities: a systematic review of interventions for alcohol reduction, smoking cessation and weight management, including meta-analysis for smoking cessation. BMJ Open. 2016;6(2):e009828.

9. Saba M, Diep J, Saini B, Dhippayom T. Meta-analysis of the effectiveness of smoking cessation interventions in community pharmacy. J Clin Pharm Ther. 2014;39(3):240-247.

10. Mdege ND, Chindove S. Effectiveness of tobacco use cessation interventions delivered by pharmacy personnel: a systematic review. Res Social Adm Pharm. 2014;10(1):21-44.

11. Munarini E, Marabelli C, Marmotti A, et al. Antismoking centres in Milan's communal pharmacies: analysis of the 2010-2011 campaign. Tumori. 2013;99(5):578-582.

12. Stead LF, Koilpillai P, Fanshawe TR, Lancaster T. Combined pharmacotherapy and behavioural interventions for smoking cessation. Cochrane Database Syst Rev. 2016;3:CD008286.

13. Silagy C, Lancaster T, Stead L, Mant D, Fowler G. Nicotine replacement therapy for smoking cessation. Cochrane Database Syst Rev. 2004;3:CD000146.

14. Stead LF, Perera R, Bullen C, et al. Nicotine replacement therapy for smoking cessation. Cochrane Database Syst Rev. 2012;11:CD000146.

15. Fiore MC. US public health service clinical practice guideline: treating tobacco use and dependence. Respir Care. 2000;45(10):1200-1262.

16. Cahill K, Stevens S, Perera R, Lancaster T. Pharmacological interventions for smoking cessation: an overview and network meta-analysis. Cochrane Database Syst Rev. 2013;5:CD009329.

17. The 2008 PHS Guideline Update Panel, Liaisons, and Staff. Treating tobacco use and dependence: 2008 update US Public Health Service Clinical Practice Guideline executive summary. Respir Care. 2008;53(9):1217-1222.

18. Legifrance.govv.fr. Article L5125-1-1 A du code de santé publique [Article L5125-1-1 A of the Public Health Code]. Available from: https://www.legifrance.gouv.fr/affichCodeArticle.do?idArticle=LEG IARTI000020890192\&cidTexte=LEGITEXT000006072665\&dateTe xte $=20110413$. Accessed November 15, 2017. French.

19. Ameli.fr. Avenant $\mathrm{N}^{\circ} 1$ a la convention nationale [Amendment No. 1 to the National Convention]. Available from: http://www.ameli.fr/ professionnels-de-sante/pharmaciens/votre-convention/conventionnationale-titulaires-d-officine/avenant-n-1-a-la-convention-nationale. php. Accessed November 15, 2017. French.

20. Giphar (Groupement Indépendant de Pharmaciens indépendants). Les Français et la pharmacie [French people and the pharmacy]. Available from: http://www.ifop.com/media/poll/2673-1-study_file.pdf. Accessed November 15, 2017. French.

21. Berlin I. Comorbidities and tobacco dependence treatment initiation. Nicotine Tob Res. 2016;18(8):1683.

22. Planetoscope. Nombre de personnes clientes d'une pharmacie en France [Number of customers of a pharmacy in France]. Available from: http://www.planetoscope.com/sante/878-nombre-de-personnesclientes-d-une-pharmacie-en-france.html. Accessed November 15, 2017. French.

23. Ordre National des Pharmaciens. Les pharmaciens - Panorama au 1er janvier 2016 [Pharmacists: Panorama on January 1, 2016]. Available from: http://www.ordre.pharmacien.fr/Communications/Elementsdemographiques/Les-pharmaciens-Panorama-au-1er-janvier-2016. Accessed November 15, 2017. French.

24. Lermenier-Jeannet A. OFDT Tabagisme et arrêt du tabac en 2016 [OFDT Smoking and stopping smoking in 2016]. Available from: http://www.ofdt.fr/ofdt/fr/tt_16bil.pdf. Accessed November 15, 2017. French.
25. Sinclair HK, Bond CM, Stead LF. Community pharmacy personnel interventions for smoking cessation. Cochrane Database Syst Rev. 2004; (1):CD003698.

26. Bouchet-Benezech B. Place du pharmacien d'officine dans la prise en charge du sevrage tabagique: résultats intermédiaires de l'étude observationnelle STOP [Place of the pharmacist in the management of smoking cessation: intermediate results of the STOP observational study]. Paris V University Memoir. 2016. French.

27. Lally P, van Jaarsveld CH, Potts HW, Wardle J. How are habits formed: modelling habit formation in the real world. Eur J Soc Psychol. 2010;40:998-1009.

28. Costello MJ, Sproule B, Victor JC, Leatherdale ST, Zawertailo L, Selby P. Effectiveness of pharmacist counselling combined with nicotine replacement therapy: a pragmatic randomised trial with 6,987 smokers Cancer Causes Control. 2011;22(2):167-180.

29. Le Faou AL, Baha M, Boussadi A. Les actualités de CDTnet: le dossier national 2015 et les taux d'abstinence chez les fumeurs reçus en 2011 et 2012 [News from CDTnet: 2015 national file and abstinence rates among smokers received in 2011 and 2012]. Presented at: 24th Seminar of Study Group on Smoking Cessation (Groupe d'étude sur le sevrage tabagique GEST); January 6, 2016; Paris. French.

30. Goldenberg M, Danovitch I, IsHak WW. Quality of life and smoking. Am J Addict. 2014;23(6):540-562.

31. Dansou A, Pousséo C, Kaniut V, Leloup A, Aubry M, Le Louarn A. L'aide au sevrage tabagique dans les officines françaises [Assessment of smoking cessation assistance in French pharmacies]. Santé Publique. 2015;27(2):167-176. French [with English abstract].

32. Le Louarn A, Gérard S. L'aide au sevrage tabagique assurée par les pharmaciens d'Alsace [Pharmacists' role in smoking cessation activities in Alsace]. Santé Publique. 2002;14(2):121-134. French [with English abstract].

33. Mautrait C. Sevrage tabagique: le conseil à l'officine [Smoking Cessation: Advice at the Pharmacy]. Le moniteur des pharmacies; 2013. French.

34. Ordre National des Pharmaciens. Sevrage tabagique: les pharmaciens sont au rendez-vous [Smoking cessation: pharmacists are participating]. Paris: 2014. Available from: http://www.ordre.pharmacien.fr/Communications/Communiques-de-presse/Sevrage-tabagique-les-pharmacienssont-au-rendez-vous. Accessed November 15, 2017. French.

35. Dreux C, Blanchet F, Collin JP, Huret N, Le Maitre B, Hirsch A. Pharmacist and smoker: a training programme for French pharmacists on practical aspects of smoking cessation. Presented at: $62^{\mathrm{e}}$ congrès de la Féderation Internationale Pharmaceutique; August 31-September 5, 2002; Nice. French.

36. Madurasinghe VW, Sohanpal R, James W, et al. Smoking treatment optimisation in pharmacies (STOP): a cluster randomised pilot trial of a training intervention. Pilot Feasibility Stud. 2017;3(1):1.

37. Shen X, Bachyrycz A, Anderson JR, Tinker D, Raisch DW. Improving the effectiveness of pharmacist-assisted tobacco cessation: a study of participant- and pharmacy-specific differences in quit rates. Ann Pharmacother. 2015;49(3):303-310.

38. Neumann T, Rasmussen M, Ghith N, Heitmann BL, Tønnesen H. The Gold Standard Programme: smoking cessation interventions for disadvantaged smokers are effective in a real-life setting. Tob Control. 2013;22(6):e9.

39. Haute Autorité de la Santé. Arrêt de la consommation de tabac: du dépistage individuel au maintien de l'abstinence en premier recours [Stopping smoking: from individual screening to maintaining abstinence as a first resort]. Available from: http://www.has-sante.fr/portail/ jcms/c_1718021/fr/arret-de-la-consommation-de-tabac-du-depistageindividuel-au-maintien-de-l-abstinence-en-premier-recours. Accessed November 15, 2017. French 


\section{Publish your work in this journal}

Substance Abuse and Rehabilitation is an international, peer-reviewed, open access journal publishing original research, case reports, editorials, reviews and commentaries on all areas of addiction and substance abuse and options for treatment and rehabilitation. The manuscript management system is completely online and includes a very quick and fair peer-review system. Visit http://www.dovepress.com/testimonials.php to read real quotes from published authors.

Submit your manuscript here: https://www.dovepress.com/substance-abuse-and-rehabilitation-journal 